\title{
Interpreting mosquito feeding patterns in Australia through an ecological lens: an analysis of blood meal studies
}

\author{
Eloise B. Stephenson ${ }^{1 *} \mathbb{D}$, Amanda K. Murphy ${ }^{2}$, Cassie C. Jansen ${ }^{3}$, Alison J. Peel ${ }^{1}$ and Hamish McCallum ${ }^{1}$
}

\begin{abstract}
Background: Mosquito-borne pathogens contribute significantly to the global burden of disease, infecting millions of people each year. Mosquito feeding is critical to the transmission dynamics of pathogens, and thus it is important to understanding and interpreting mosquito feeding patterns. In this paper we explore mosquito feeding patterns and their implications for disease ecology through a meta-analysis of published blood meal results collected across Australia from more than 12,000 blood meals from 22 species. To assess mosquito-vertebrate associations and identify mosquitoes on a spectrum of generalist or specialist feeders, we analysed blood meal data in two ways; first using a novel odds ratio analysis, and secondly by calculating Shannon's diversity scores.

Results: We find that each mosquito species had a unique feeding association with different vertebrates, suggesting species-specific feeding patterns. Broadly, mosquito species could be grouped broadly into those that were primarily ornithophilic and those that fed more often on livestock. Aggregated feeding patterns observed across Australia were not explained by intrinsic variables such as mosquito genetics or larval habitats. We discuss the implications for disease transmission by vector mosquito species classified as generalist-feeders (such as Aedes vigilax and Culex annulirostris), or specialists (such as Aedes aegypti) in light of potential influences on mosquito host choice.

Conclusions: Overall, we find that whilst existing blood meal studies in Australia are useful for investigating mosquito feeding patterns, standardisation of blood meal study methodologies and analyses, including the incorporation of vertebrate surveys, would improve predictions of the impact of vector-host interactions on disease ecology. Our analysis can also be used as a framework to explore mosquito-vertebrate associations, in which host availability data is unavailable, in other global systems.
\end{abstract}

Keywords: Blood meal, Associations, Vector, Vertebrate, Disease risk, Blood-feeding

\section{Background}

Mosquitoes are the most important disease vector globally, responsible for infecting millions of people and animals annually with pathogens that influence human health, livestock and economic trade and wildlife biodiversity [1]. Mosquitoes comprise a broad taxonomic group with more than 3000 species recognised across 40 genera [2], but not all species are involved in pathogen transmission. Pathogen transmission requires a mosquito

\footnotetext{
*Correspondence: eloise.stephenson@griffithuni.edu.au

1 Environmental Futures Research Institute, Griffith University, Brisbane,

QLD 4111, Australia

Full list of author information is available at the end of the article
}

to take a blood meal from a source host and then to subsequently feed on a recipient host. Understanding the feeding patterns of mosquitoes can inform disease management strategies (such as targeted vector control to reduce vector-host contact) and can contribute to models forecasting future disease risk in human and animal populations [3].

Mosquito host choice is complex; both intrinsic and extrinsic factors can influence feeding preference $[3,4]$. Intrinsic variables can include genetics, whereby individuals are more likely to feed on the same host as previous generations $[5,6]$, and the nutritional state of the mosquito, with nutrition-poor individuals being more likely 
to feed on non-preferred hosts [4]. Extrinsic host-seeking behaviour is predominantly guided by detection of heat and carbon dioxide $\left(\mathrm{CO}_{2}\right)$, and is also affected by host abundance, biomass, various odorants and chemicals that are released by hosts, and host defensive behaviour [7-13]. Other extrinsic factors may include climatic variables such as relative humidity, along with habitat characteristics that determine availability and diversity of hosts $[12,14]$. In addition to these broad intrinsic and extrinsic variables, evidence suggests that mosquitoes may adjust their host-seeking behaviours based on positive and negative experiences, in essence, adapting feeding choices according to their individual circumstances [4].

Mosquito-host relationships in Australia are largely understudied. The island biogeography of Australia and its varied climatic zones and bioregions promote a unique endemic biodiversity for mosquito and vertebrate host species. Along with a high diversity of native marsupials, placental mammals and birds in Australia, there are more than 300 species of mosquitoes described, many of which are unique to the continent [15]. The interactions between these populations of mosquitoes and vertebrate hosts across different climatic zones provide opportunities for maintenance and emergence of mosquito-borne pathogens. The transmission of numerous medicallyimportant arboviruses has been documented in Australia to date, including dengue (DENV), Ross River (RRV), Murray valley encephalitis (MVEV), Barmah Forest (BFV) and Kunjin [16] viruses.

Taking into account the complexity of contributing factors, critical analysis of the feeding patterns of mosquitoes may represent an important approach to explore disease risks for both human and animal populations. This study aims to synthesise existing literature describing blood meal studies in Australia, specifically assessing the most likely mosquito-host associations, and the diversity of feeding patterns for common mosquito species. In light of these feeding patterns, we discuss broad implications for disease ecology.

\section{Methods}

\section{Data collection}

Original research articles were systematically searched by using the following search terms in different combination across five search engines (Web of Science, ProQuest, Science Direct, PubMed and Google Scholar): 'bloodmeal", 'blood meal', blood-meal', 'feeding,' 'habit', 'pattern"', 'preference"', 'interaction"', 'mosquito"', 'vector"', 'vector-host', 'host", 'vertebrate",' 'animal"' and 'Australia. The asterisk $(*)$ operator was used as a wildcard to search for all possible variations of keywords. We then manually searched the reference lists of papers to identify additional relevant articles. Papers were included in this review if they were original peer-reviewed research articles, undertaken on mainland Australia (e.g. [17] was undertaken in Badu Island in the Torres Strait and thus excluded), analysed field-collected mosquitoes that had fed under natural conditions on free-living vertebrates (e.g. [18] used tethered animal baits and was excluded), and assessed at least 3 potential vertebrate species (e.g. [19] only tested for a single flying fox species, and was excluded).

The following information was extracted from identified articles: the geographical area in which the study took place, including site location, bioregion of each site (as defined by Thackway \& Cresswell [20]), the mosquito collection method used (including the year, month and collection method/trap type), and the methods used to determine the vertebrate origin of blood meals (including the vertebrate species investigated, the source of vertebrate reference samples and laboratory technique). Additional notes were made on stated limitations (if any) of each paper and whether data on vertebrate abundance and diversity was included. A database of blood meal results was populated and is reported in Additional file 1: Table S1.

\section{Data analysis \\ Mosquito-vertebrate associations}

Odds ratios were used to calculate the direction (positive or negative) and strength of associations in the database between each mosquito species and vertebrate taxon. For this analysis, the blood meal origin data compiled from the literature were aggregated such that each vertebrate species was grouped into the broader taxonomic groups of humans, Carnivora (cats, dogs and foxes), Aves (all birds), Diprotodontia (all possum and kangaroo species), Artiodactyla (cows, sheep, pigs and goats) and Perissodactyla (horses). Flying fox [21], rodent [22, 23] and rabbit $[22,24]$ species were excluded from this analysis, as the sample size of blood meals from these species was too small (either one or two studies, with these species comprising less than $9 \%$ of blood-meal origins within each). To be included in the analysis, mosquito species needed to meet all minimum data criteria of (i) their blood meal origins being reported more than twice in the literature; and (ii) having an arbitrary minimum of 35 blood meals identified.

Log odds ratios were calculated between each mosquito and vertebrate taxon using two by two feeding frequency tables, derived from the raw data (Additional file 1: Table S2). Positive log odds ratios indicate a positive feeding association between a given mosquito species and vertebrate host, whereby there is a higher likelihood than random chance that a blood meal of that mosquito species would originate from the given vertebrate taxon. 
The greater the log odds ratio, the stronger the feeding association. Conversely, a negative log odds ratio suggests a negative feeding association, whereby there is a lower likelihood that a blood meal from the mosquito species would originate from the given vertebrate taxon. Log odds ratios close to 0 indicate no association between the mosquito species and vertebrate taxon.

The log odds ratios were plotted in a heatmap chart and sorted using hierarchical clustering. The clustering grouped mosquitoes with similar feeding patterns together by similarity in log odds ratio across all vertebrate taxa. All calculations and graphs were generated using R software, with packages gplots and RColorBrewer [25] with modified script from Raschka [26].

\section{Mosquito feeding diversity}

We used the Shannon's diversity index to place mosquito species on a spectrum between generalist or specialist feeders. The inclusion criteria for this analysis were that each mosquito species needed to have fed on greater than three vertebrate species and had to have a minimum number of 10 blood meals analysed. Vertebrates were not aggregated by taxonomic group in this analysis but remained at the level reported in the literature (mostly as species but, for the case of birds, several studies reported as class). A total of 15 vertebrate species were included in this analysis as blood-meal origins, and 13,934 blood meals from 21/41 mosquito species met the criteria (Additional file 1: Table S1).

Shannon's diversity index was calculated for each mosquito species [27] and expressed as an h-index. A higher h-index is associated with a greater feeding diversity, as it suggests a mosquito species has fed on a greater number of vertebrate species and/or feeds evenly across vertebrates. Conversely, a lower h-index suggests mosquito species have a low feeding diversity, and are associated with feeding on fewer vertebrate species and/or a greater number of feeds on a small number of vertebrates. Within this dataset, we categorised an h-index in the top quartile as 'high feeding diversity', whilst an h-index in the lowest quartile was considered a 'low feeding diversity'. Shannon's diversity index was calculated in Excel.

\section{Results}

\section{Characteristics of the selected studies}

We identified ten papers that met the search criteria, comprising 14,044 mosquito blood meals across 48 mosquito species. Study characteristics and methodologies are summarised in Table 1. These studies took place at 32 sites across 14 bioregions, in all mainland states and territories in Australia (Fig. 1). The selected studies were undertaken over a 62 year-period, from 1954 to 2016.
To collect blood-fed mosquitoes, most studies $(n=$ 8) used Centers for Disease Control (CDC) $\mathrm{CO}_{2}$-baited miniature light traps [28], supplemented with 1-octen3-ol in some cases (Table 1). Other methods included unbaited BioGent ${ }^{\circledR}$ (BG) sentinel traps [22] and aspiration of resting sites [21, 29, 30]. One study [29] also used vehicle-mounted traps. To analyse blood meals, early studies employed precipitin tests [29-31] and serological gel diffusion techniques [32, 33] (Table 1). More recent studies adopted enzyme-linked immunosorbent assay (ELISA) and various molecular techniques including polymerase chain reaction (PCR) and gene sequencing [2224, 34]. Vertebrate reference sources most commonly employed in immunoassays and gel diffusion techniques were commercially-available anti-sera and included horse, rabbit, rat, dog, chicken, cat, bird, kangaroo, cow and pig. Molecular studies which included wildlife used vertebrate references provided through wildlife hospitals, zoos and roadkill. These studies also included DNA sequence data available on GenBank.

\section{Mosquito-vertebrate associations}

Of the 10 studies of blood meal origins, data on 41 mosquito species were reported, and data on 12 of these met the criteria to be included in analysis: Aedes normanensis, Ae. notoscriptus, Ae. procax, Ae. vigilax, Anopheles annulipies, An. bancroftii, Coquillettidia linealis, Cq. xanthogaster, Culex annulirostris, Cx. sitiens, Cx. quinquefasciatus and Mansonia uniformis (Fig. 2). All species, except Ae. procax, showed significant positive associations with at least one vertebrate host. The strongest positive log odds ratio was between $C x$. annulirostris and the Diprotodontia taxa (possums and kangaroos; log odds ratio $(\mathrm{LOR})=2.77)$, followed by $M a$. uniformis and humans $(\mathrm{LOR}=2.2)$. All mosquito species except $A e$. vigilax and $C q$. xanthogaster had strong negative association with at least one vertebrate taxon. The strongest negative $\log$ odds ratio was between $C x$. quinquefasciatus and Diprotodontia ( $\mathrm{LOR}=-3.8$ ), followed by Ae. notoscriptus and Artiodactyla (cows, sheep, pigs and goats; $\mathrm{LOR}=-2.8$ ).

The mosquito species clustered together in two broad groups. The first cluster group consisted of seven mosquito species (Cx. quinquefasciatus, Ae. vigilax, Cq. xanthogaster, Ae. procax, Cq. linealis, Cx. sitiens and Ae. notoscriptus), of which most shared a negative association with the Artiodactyla (6 of the 7 species) and Diprotodontia vertebrates (5/7), and a positive association with humans (7/7) and Aves (6/7). Within this cluster, Ae. vigilax and $C q$. xanthogaster were in the same clade and shared a strong positive association with Perissodactyla. Coquillettidia linealis and Cx. sitiens also shared a clade 


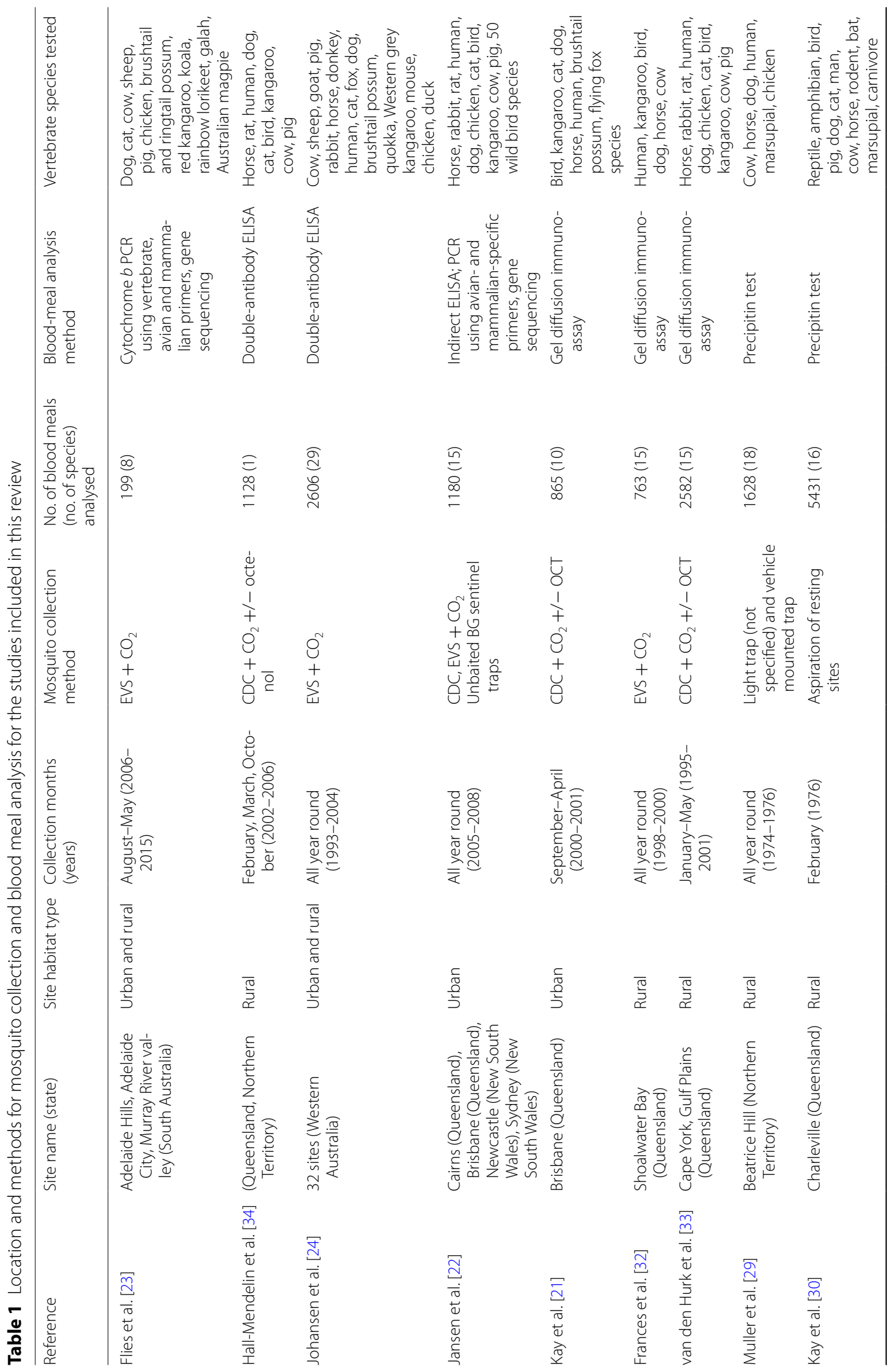




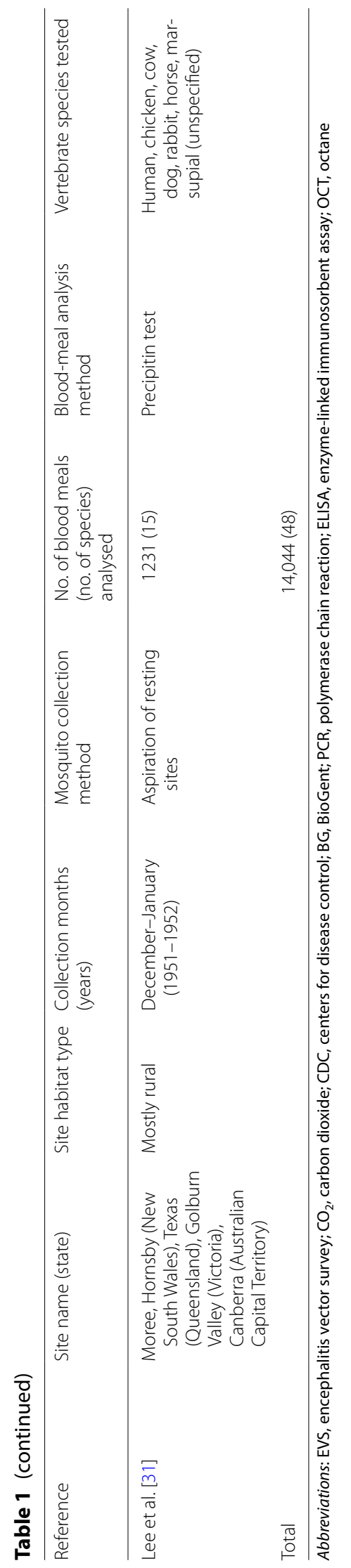




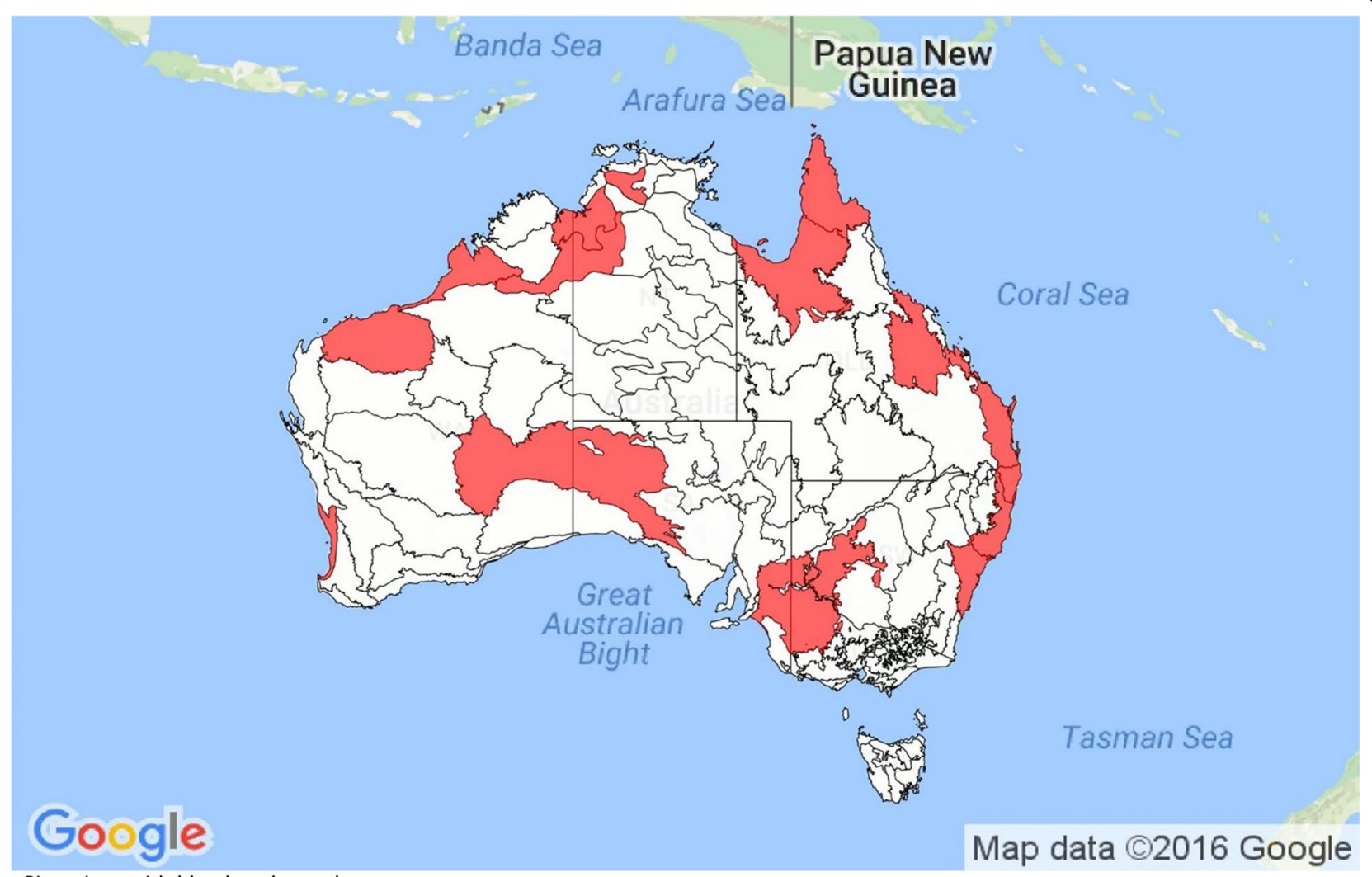

Bioregions with bloodmeal samples

Fig. 1 Bioregions in which blood meal studies took place (indicated in red) across Australia (derived from Google Map Data ())

and strong negative association with both Artiodactyla and Carnivora.

The second major cluster group consisted of five mosquito species (Cx. annulirostris, Ae. normanesis, An. annulipies, An. bancroftii and Ma. uniformis). These species all shared a positive association with Artiodactyla and a negative association with Aves. Culex annulirostris and Ae. normanesis were on the same clade and shared a strong positive association with Perissodactyla and Diprotodontia. Although they both also had a negative association with Aves, Carnivora and humans, this was strongest only for Ae. normanensis. Anopheles annulipies and Ma. uniformis were on a single clade and were both had high associations with humans.

\section{Mosquito feeding diversity}

Twenty-two mosquito species met the criteria for inclusion in the diversity analysis based on Shannon's index (Fig. 3), comprising 12,424 individual blood meals in total. The median h-index reported across all species was 1.40 , and the mean was 1.34 . Low feeding diversity (h-index $=<0.99$ ) was observed in five mosquito species; of which Ae. aegypti had the lowest diveristy $($ h-index $=0.72)$. High feeding diversity (h-index $=>1.64)$ was reported in five mosquito species; of these, Ae. vigilax had the highest diversity ( $\mathrm{h}$-index $=2.17$ ).

\section{Discussion}

Our analysis revealed that each mosquito species had a unique feeding association with different vertebrates, suggesting species-specific feeding patterns. The hierarchical clustering from the odds ratio analysis sorted mosquitoes into two broad groups: mosquitoes that either had a positive association with birds (Aves) and negative association with livestock (Artiodactyla), or vice-versa. Interpreting the feeding patterns of these particular mosquito species is important, given that at least half of these mosquitoes have been found to be competent vectors for notifiable arboviruses in Australia [35-40], whilst the other half have been demonstrated to carry some viruses, although their ability to transmit them has not been fully investigated [41-43].

Intrinsic drivers of mosquito host choices (such as genetics, larval ecology and dispersal) did not explain feeding patterns in this analysis. Specifically, mosquito species did not group together by taxonomic relatedness (e.g. genus). Studies examining the effect of genetics on mosquito host choices have found that offspring 


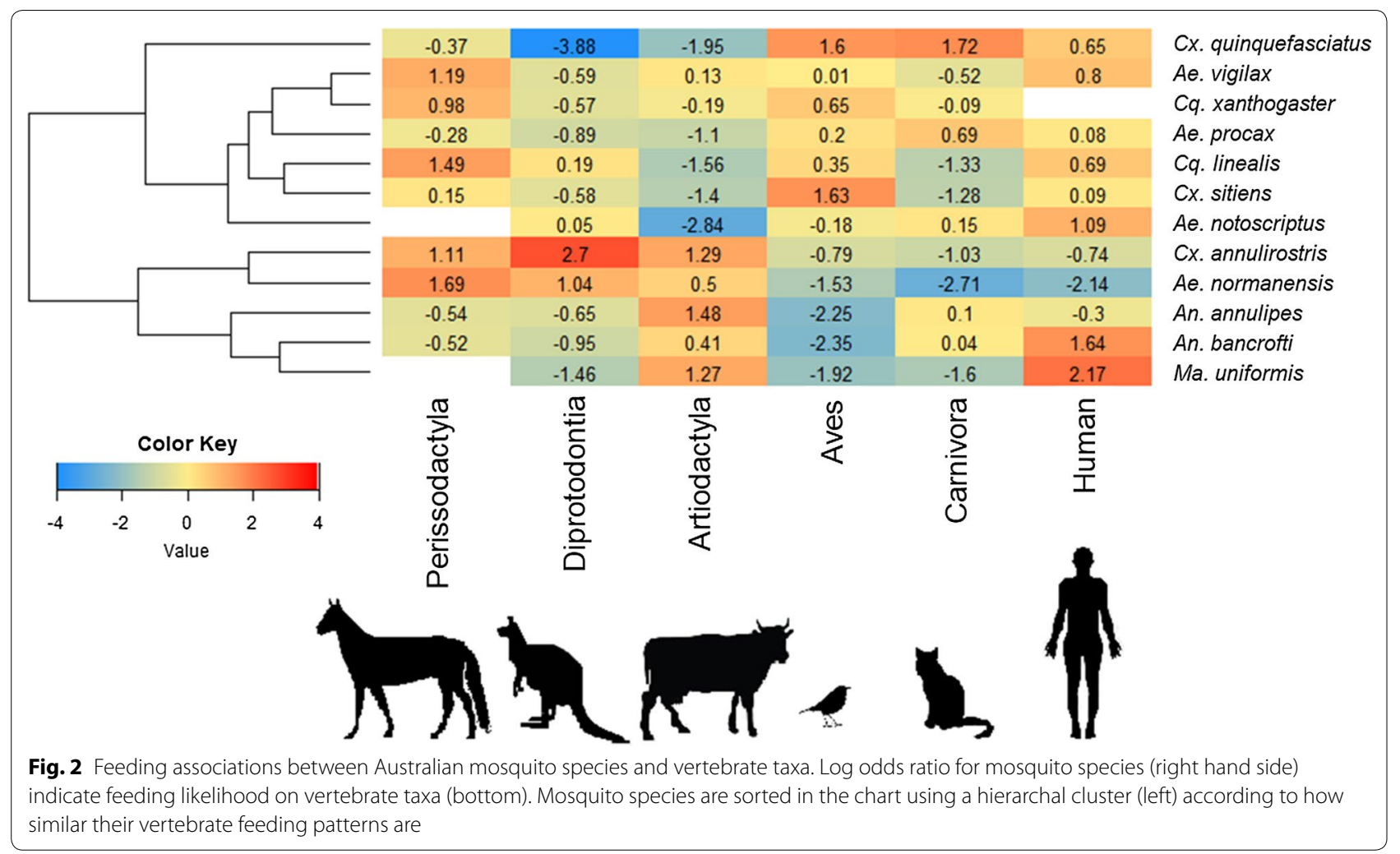

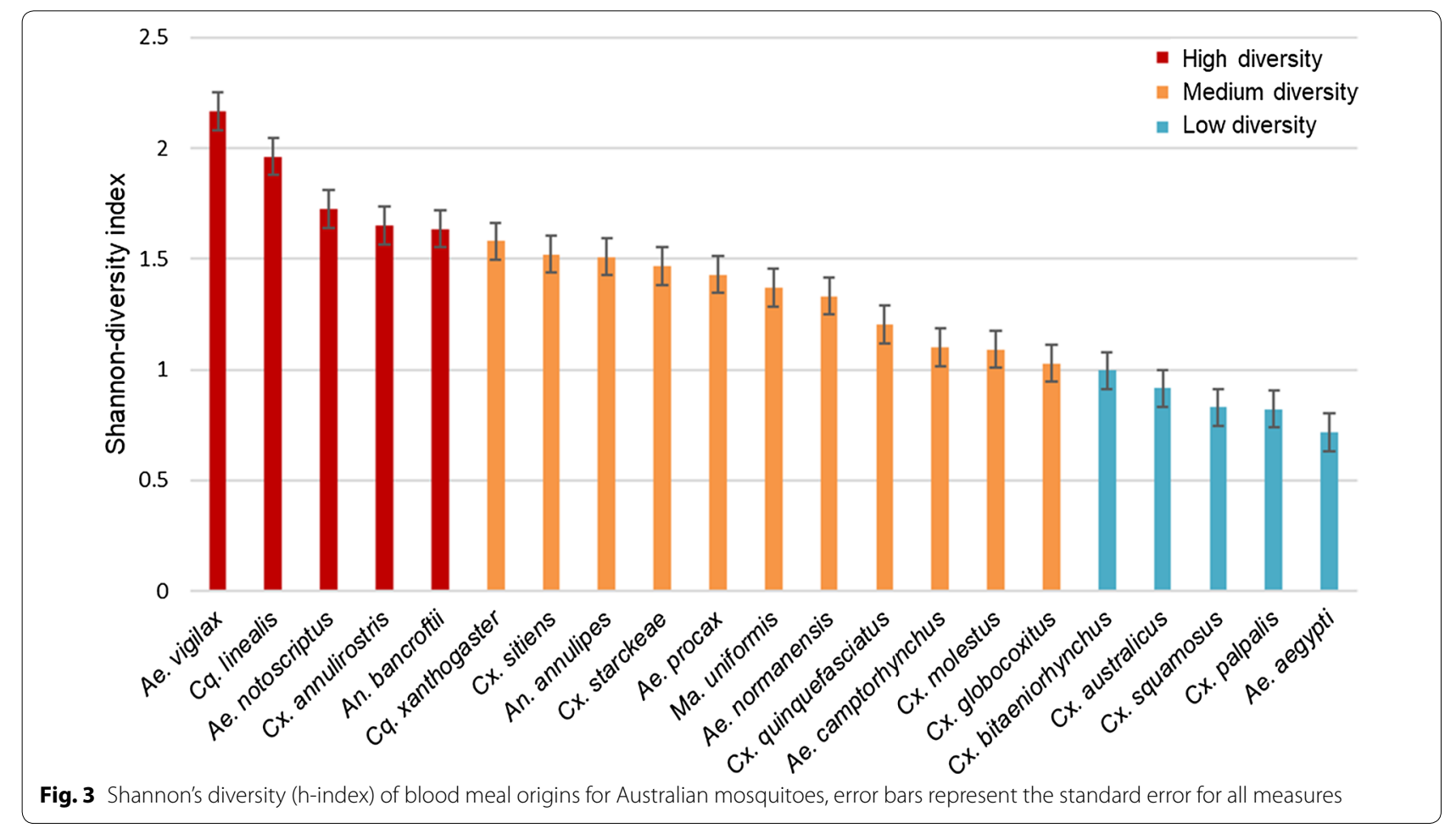


are more likely to feed on the same host as previous generations $[5,6]$. However, this has only been demonstrated within-species and is unlikely to be important between species belonging to same genus, particularly since potential for rapid evolution (due to short generation span) likely reduces the influence that taxonomic relatedness may have on mosquito feeding host behaviour. Another intrinsic factor, mosquito larval ecology, may partially explain some clustering. For example, $A e$. normanensis and $C x$. annulirostris grouped together and larvae of both typically inhabit inland freshwater; similarly, the larval habitat of both An. bancroftii and Ma. uniformis is freshwater swamps. Although this pattern did not explain all clusters, it implies that local environmental influences, at least partially, drive mosquito host choice. This is perhaps not surprising when considering potential limitations on dispersal from larval habitats for various mosquito species. For example, Ae. vigilax is recognised as having large dispersal capability, being found more than $50 \mathrm{~km}$ from potential saltwater larval habitats, albeit likely wind-assisted in some cases [44]. This high dispersal potential suggests that Ae. vigilax can move readily between locations, allowing feeding on a diversity of vertebrate taxa, as reflected in our feeding diversity analysis. As such, whilst genetics and larval habitats may be important within species on a local scale, they do not explain the aggregated feeding patterns observed across Australia.

Extrinsic variables, such as species abundance and diversity, explain in part some of the feeding associations in this analysis, but not all. Mosquitoes have complex interactions with their environment. Thus, factors broader than vertebrate abundance alone are important to consider for mosquito feeding patterns. For example, mosquito flying/resting height has been linked to host feeding patterns [45-48]. In two Australian studies, more $C x$. sitiens and $C x$. quiquefasciatus were caught in traps set at least $8 \mathrm{~m}$ off the ground, whilst a higher abundance of Ae. vigilax were found in traps $1.5 \mathrm{~m}$ off the ground, for the same locations [47, 48]. In our meta-analysis, $C x$. sitiens and $C x$. quinquefasciatus had strong positive associations with blood meals originating from tree dwelling bird species (i.e. Australasian figbirds Sphecotheres vieilloti, common myna Sturnus tristis and helmeted friarbirds Philemon buceroides [22]), whilst Ae. vigilax had the strongest positive associations with ground-dwelling species (horses and humans). This could suggest that whilst overall vertebrate abundance within a given environment can influence the availability of a particular host, mosquitoes are highly mobile and may seek a blood meal across ecological niches within a given habitat. Thus, different mosquito species can exhibit different feeding patterns despite being exposed to the same vertebrates in a single location.

In the odds ratio analysis, $C x$. annulirostris exhibited an unexpected feeding pattern. This species is considered an important vector for medically-important arboviruses [36, 49, 50]; however, the meta-analyses which included more than 5700 blood meals, found that $C x$. annulirostris had only a weak feeding association with humans $(\mathrm{LOR}=-0.74)$. This is consistent with an early field study assessing mosquito feeding preferences using live baits, in which $C x$. annulirostris preferred cows, pigs and dogs more than humans [37]. The analysis based on Shannon's diversity, along with other studies, have identified $C x$. annulirostris as a generalist feeder with plastic feeding patterns that may shift temporally or spatially $[51,52]$. This knowledge, in combination with the widespread distribution of $C x$. annulirostris across Australia, suggests that localised studies of $C x$ annulirostris feeding are required to assess the role the species plays in disease transmission for which it is theoretically an important vector.

In addition to $C x$. annulirostris, Aedes vigilax and Ae. notoscriptus were identified as generalists due to their high diversity scores in the Shannon's diversity analysis. International studies [53-55] suggest that generalist feeders are capable of playing a role as bridge vectors due to their ability to acquire pathogens from animal hosts, and subsequently transmitting the pathogen to humans. Bridge vectors are particularly important for enzootic amplification of arboviruses and are often associated with outbreaks [53]. For the species identified in this analysis as generalists, they have been demonstrated to be competent vectors of zoonotic arboviruses in Australia $[45,56-58]$, and as such should be closely monitored to reduce transmission between vectors and humans.

The disease ecology associated with specialist feeders is also important to consider. Here we identified Ae. aegypti as having the lowest feeding diversity, indicating the species is a specialist feeder. Indeed, more than $70 \%$ of the blood meals originated from humans. The anthropophilic feeding observed in Ae. aegypti is similar to that reported in international studies, where $80-99 \%$ of all blood meals are human in origin $[59,60]$. This feeding pattern for $A e$. aegypti is consistent with its role as an important vector of several arboviruses which are transmitted between humans without an animal reservoir, including dengue, Zika and chikungunya viruses. Interestingly, although the importance of Ae. aegypti is recognised, under laboratory conditions the species has been observed to demonstrate relatively poor transmission rates for DENV, when compared to other mosquito species [61, 62]. In this case, being a specialist feeder, preferring mainly humans, is 
what determines the status of Ae. aegypti as an important disease vector, rather than its competence [63].

\section{Future directions}

An absence of data on host availability in the regions where mosquitoes were collected limits inferences on host preference specifically. Of the blood meal studies reviewed here, only one considered host abundance [21]. That study assessed abundance through a local resident survey on the number of pets, people and estimated number of possums in the vicinity, adding confidence to the interpretation of vector-feeding patterns. Such collection of host ecology data in conjunction with bloodfed mosquitoes can be considerably labour-intensive; however, it provides a more thorough assessment of how host abundance and biomass may influence observed mosquito feeding patterns and informs the selection of appropriate reference samples against which to compare blood meals in the laboratory. Although limited in their application, other blood-meal studies $[64,65]$ have utilised databases, such as the Atlas of Living Australia (ALA) or the Global Biodiversity Information Facility (GBIF), to identify potential available vertebrates in the absence of formal vertebrate surveys. Whilst they are no substitute for vertebrate surveys, these datasets could be beneficial for noting the presence of common hosts in future blood meal studies but are limited in estimating host density or true absence of a given species.

Although a range of reference vertebrates were often included in Australian blood-meal studies, they were rarely a true representation of the vertebrates available to mosquitoes for feeding. At present there are large gaps in understanding the role of cryptic, migratory or smaller mammalian species in mosquito feeding patterns. For example, only two studies included rabbits [22, 24] and rodents $[22,23]$ in their analysis. Despite their small size, rabbits and rodents were identified to be the origin of blood meals for Cx. sitiens and Cq. linealis [22]. Mosquito-rodent associations have also been identified in the literature, where by at least $27 \%$ of mice were seropositive to RRV $[58,66]$. It is therefore important that, despite small body size, rats and rodents are included in future investigations of mosquito blood meals.

\section{Conclusions}

Improved understanding of mosquito feeding patterns can lead to better management and risk predictions for medically important arboviruses. Here we find that of the Australian mosquito species tested, each had a unique feeding pattern; however, the particular specialist or generalist feeding patterns of mosquito species could be a key determinant of the risk they pose for human disease. These patterns, and the resulting human disease risk, are likely influenced by a suite of intrinsic and extrinsic variables. Broader ecological considerations alongside these feeding patterns could be useful for the interpretation of these complex biological systems, but at present data available to do this are limited. Future studies should utilise multidisciplinary approaches to collect data on vertebrate communities in parallel with mosquito communities. More data from both top-down (broad assessments of blood meals) and bottom-up approaches (specialised host choice experiments) are needed in conjunction with modelling techniques to bring these data together for meaningful interpretation of arbovirus transmission risk in Australia.

\section{Additional file}

Additional file 1: Table S1. Reported blood-meal results for Australian mosquito species. Numbers in the columns representing number of blood meals for each vertebrate. Table S2. Derivation of $2 \times 2$ contingency tables for mosquito feeding preferences.

\section{Acknowledgements \\ Not applicable. \\ Funding \\ ES was supported by Australian Government Research Training Program Scholarship.}

\section{Availability of data and materials}

The datasets used and/or analysed during the present study are available from the corresponding author upon reasonable request.

\section{Authors' contributions}

ES collected, analysed, interpreted papers and was a major contributor in the writing of the manuscript. AM, CC, AP and HM contributed to the interpretation of results and writing of the manuscript. All authors read and approved the final manuscript.

\section{Ethics approval and consent to participate}

Not applicable.

\section{Consent for publication}

Not applicable.

\section{Competing interests}

The authors declare that they have no competing interests.

\section{Publisher's Note}

Springer Nature remains neutral with regard to jurisdictional claims in published maps and institutional affiliations.

\section{Author details \\ ${ }^{1}$ Environmental Futures Research Institute, Griffith University, Brisbane, QLD 4111, Australia. ${ }^{2}$ QIMR, Herston, QLD 4006, Australia. ${ }^{3}$ Communicable Diseases Branch, Department of Health, Queensland Government, Herston, QLD 4006, Australia.}

Received: 15 November 2018 Accepted: 20 March 2019

Published online: 04 April 2019 


\section{References}

1. Gubler DJ. Human arbovirus infections worldwide. Ann NY Acad Sci. 2001;951:13-24

2. Wongkamchai $S$, Khongtak $P$, Leemingsawat $S$, Komalamisra N, Junsong $\mathrm{N}$, Kulthanan K, et al. Comparative identification of protein profiles and major allergens of saliva, salivary gland and whole body extracts of mosquito species in Thailand. Asian Pac J Allergy Immunol. 2010;28:162-9.

3. Lyimo IN, Ferguson HM. Ecological and evolutionary determinants of host species choice in mosquito vectors. Trends Parasitol. 2009;25:189-96.

4. Takken W, Verhulst NO. Host preferences of blood-feeding mosquitoes. Annu Rev Entomol. 2013;58:433-53.

5. Mukwaya L. Genetic control of feeding preferences in the mosquitoes Aedes (Stegomyia) simpsoni and aegypti. Physiol Entomol. 1977;2:133-45.

6. Ulloa García A, Arredondo Jiménez JI, Fernández Salas I, Rodríguez MH, González Cerón L. Innate host selection in Anopheles vestitipennis from southern Mexico. J Am Mosq Control Assoc. 2004;20:337-41.

7. Edman JD, Taylor DJ. Culex nigripalpus: seasonal shift in the bird-mammal feeding ratio in a mosquito vector of human encephalitis. Science. 1968;161:67-8.

8. Balenghien T, Fouque F, Sabatier P, Bicout DJ. Horse-, bird-, and humanseeking behavior and seasonal abundance of mosquitoes in a West Nile virus focus of southern France. J Med Entomol. 2006;43:936-46.

9. Kilpatrick AM, Kramer LD, Jones MJ, Marra PP, Daszak P. West Nile virus epidemics in North America are driven by shifts in mosquito feeding behavior. PLoS Biol. 2006;4:e82.

10. Eiras $A E$, Jepson P. Responses of female Aedes aegypti (Diptera: Culicidae) to host odours and convection currents using an olfactometer bioassay. Bull Entomol Res. 1994;84:207-11.

11. Bowen M. The sensory physiology of host-seeking behavior in mosquitoes. Ann Rev Entomol. 1991;36:139-58.

12. Clements A. The biology of mosquitoes. London: Chapman \& Hall; 1992

13. Day JF, Ebert KM, Edman JD. Feeding patterns of mosquitoes (Diptera: (Culicidae) simultaneously exposed to malarious and healthy mice, including a method for separating blood meals from conspecific hosts. J Med Entomol. 1983;20:120-7.

14. Olanga EA, Okal MN, Mbadi PA, Kokwaro ED, Mukabana WR. Attraction of Anopheles gambiae to odour baits augmented with heat and moisture. Malar J. 2010;9:6.

15. Webb C, Russell R, Doggett S. A guide to mosquitoes of Australia. New York: CSIRO Publishing; 2016.

16. van den Hurk AF, Jansen CC. Arboviruses of Oceania. In: Loukas A, editor. Neglected tropical diseases - Oceania. Berlin: Springer; 2016. p. 193-235.

17. van den Hurk AF, Nisbet DJ, Johansen CA, Foley PN, Ritchie SA, Mackenzie JS. Japanese encephalitis on Badu Island, Australia: the first isolation of Japanese encephalitis virus from Culex gelidus in the Australasian region and the role of mosquito host-feeding patterns in virus transmission cycles. Trans R Soc Trop Med Hyg. 2001;95:595-600.

18. Muller M, Murray M. Blood-sucking flies feeding on sheep in eastern Australia. Aust J Zool. 1977;25:75-85.

19. Ryan PA, Martin L, Mackenzie JS, Kay BH. Investigation of gray-headed flying foxes (Pteropus poliocephalus) (Megachiroptera: Pteropodidae) and mosquitoes in the ecology of Ross River virus in Australia. Am J Trop Med Hyg. 1997;57:476-82.

20. Thackway R, Cresswell I. A bioregional framework for planning the national system of protected areas in Australia. Nat Areas J. 1997;17:241-7.

21. Kay BH, Boyd AM, Ryan PA, Hall RA. Mosquito feeding patterns and natural infection of vertebrates with Ross River and Barmah Forest viruses in Brisbane, Australia. Am J Trop Med Hyg. 2007;76:417-23.

22. Jansen CC, Webb CE, Graham GC, Craig SB, Zborowski P, Ritchie SA, et al. Blood sources of mosquitoes collected from urban and peri-urban environments in eastern Australia with species-specific molecular analysis of avian blood meals. Am J Trop Med Hyg. 2009;81:849-57.

23. Flies EJ, Flies AS, Fricker SR, Weinstein P, Williams CR. Regional comparison of mosquito bloodmeals in South Australia: implications for Ross River virus ecology. J Med Entomol. 2016;53:902-10.

24. Johansen CA, Power SL, Broom AK. Determination of mosquito (Diptera: Culicidae) bloodmeal sources in Western Australia: implications for arbovirus transmission. J Med Entomol. 2009:46:1167-75.

25. Neuwirth E. Package 'RColorBrewer'. 2015. http://www.colorbrewe r2.org.
26. Raschka S. Instant heat maps in R: how-to. Birmingham UK: Packt Publishing Ltd.; 2013.

27. Morris EK, Caruso T, Buscot F, Fischer M, Hancock C, Maier TS, et al. Choosing and using diversity indices: insights for ecological applications from the German Biodiversity Exploratories. Ecol Evol. 2014;4:3514-24.

28. Sudia W, Chamberlain R. Battery-operated light trap, an improved model. Mosq News. 1962;22:126-9.

29. Muller M, Murray M, Edwards J. Blood-sucking midges and mosquitoes feeding on mammals at Beatrice Hill, NT. Aust J Zool. 1981;29:573-88.

30. Kay B, Boreham P, Williams G. Host preferences and feeding patterns of mosquitoes (Diptera: Culicidae) at Kowanyama, Cape York Peninsula, northern Queensland. Bull Entomol Res. 1979;69:441-57.

31. Lee DJ, Clinton K, O'gower A. The blood sources of some Australian mosquitoes. Aust J Biol Sci. 1954;7:282-301.

32. Frances SP, Cooper RD, Rowcliffe KL, Chen N, Cheng Q. Occurrence of Ross River virus and Barmah Forest virus in mosquitoes at Shoalwater Bay military training area, Queensland, Australia. J Med Entomol. 2004:41:115-20.

33. van den Hurk AF, Johansen CA, Zborowski P, Paru R, Foley PN, Beebe NW, et al. Mosquito host-feeding patterns and implications for Japanese encephalitis virus transmission in northern Australia and Papua New Guinea. Med Vet Entomol. 2003;17:403-11.

34. Hall-Mendelin S, Jansen CC, Cheah WY, Montgomery BL, Hall RA, Ritchie SA, et al. Culex annulirostris (Diptera: Culicidae) host feeding patterns and Japanese encephalitis virus ecology in northern Australia. J Med Entomol. 2012:49:371-7

35. Watson TM, Kay BH. Vector competence of Aedes notoscriptus (Diptera: Culicidae) for Barmah Forest virus and of this species and Aedes aegypti (Diptera: Culicidae) for dengue 1-4 viruses in Queensland. Australia. J Med Entomol. 1999:36:508-14.

36. Boyd AM, Kay BH. Vector competence of Aedes aegypti, Culex sitiens, Culex annulirostris, and Culex quinquefasciatus (Diptera: Culiciclae) for Barmah Forest virus. J MedEntomol. 2000;37:660-3.

37. Ryan PA, Kay BH. Vector competence of mosquitoes (Diptera: Culicidae) from Maroochy Shire, Australia, for Barmah Forest virus. J Med Entomol. 1999;36:856-60.

38. Wells PJ, Russell RC, Cloonan MJ. Investigating vector competence of Culex annulirostris and Aedes vigilax for Ross River virus and other alphaand bunyaviruses. Arbov Res Aust. 1993;6:10-4.

39. Kay BH, Fanning ID, Carley JG. Vector competence of Culexpipiens quinquefasciatus for Murray Valley encephalitis, Kunjin, and Ross River viruses from Australia. Am J Trop Med Hyg. 1982;31:844-8.

40. Kay BH, Carley JG, Fanning ID, Filippich C. Quantitative studies of the vector competence of Aedes aegypti, Culex annulirostris and other mosquitos (Diptera, Culicidae) with Murray Valley encephalitis and other Queensland arboviruses. J Med Entomol. 1979;16:59-66.

41. Jeffery JA, Ryan PA, Lyons SA, Kay BH. Vector competence of Coquillettidia linealis (Skuse) (Diptera: Culicidae) for Ross River and Barmah Forest viruses. Aust J Entomol. 2002;41:339-44.

42. van den Hurk AF, Nisbet DJ, Foley PN, Ritchie SA, Mackenzie JS, Beebe NW. Isolation of arboviruses from mosquitoes (Diptera: Culicidae) collected from the Gulf Plains region of Northwest Queensland, Australia. J Med Entomol. 2002;39:786-92.

43. Harley D, Phillips D, Ritchie S, Atkin C, van den Hurk A. Isolation of Ross River virus from mosquitoes trapped in North Queensland. Arbov Res Aust. 1997:7:92-4.

44. Chapman HF, Hughes JM, Jennings C, Kay BH, Ritchie SA. Population structure and dispersal of the saltmarsh mosquito Aedes vigilax in Queensland, Australia. Med Vet Entomol. 1999;13:423-30.

45. Lee HI, Seo BY, Shin EH, Burkett DA, Lee WJ, Shin YH. Study of flying height of culicid species in the northern part of the Republic of Korea. J Am Mosq Cont Assoc. 2006;22:239-45.

46. Swanson D, Adler P. Vertical distribution of haematophagous Diptera in temperate forests of the southeastern USA. Med Vet Entomol. 2010:24:182-8

47. Jansen CC, Zborowski P, Ritchie SA, Van Den Hurk AF. Efficacy of birdbaited traps placed at different heights for collecting ornithophilic mosquitoes in eastern Queensland, Australia. Aust J Entomol. 2009;48:53-9.

48. Johnston E, Weinstein P, Slaney D, Flies AS, Fricker S, Williams C. Mosquito communities with trap height and urban-rural gradient in Adelaide, 
South Australia: implications for disease vector surveillance. J Vect Ecol. 2014;39:48-55.

49. Jansen CC, Webb CE, Northill JA, Ritchie SA, Russell RC, van den Hurk AF. Vector competence of Australian mosquito species for a North American strain of West Nile virus. Vector Borne Zoonotic Dis. 2008;8:805-11.

50. Kay BH, Hearnden MN, Oliveira NM, Sellner IN, Hall RA. Alphavirus infection in mosquitoes at the Ross River reservoir, north Queensland, 1990-1993. J Am Mosq Cont Assoc. 1996;12:421-8.

51. Williams CR, Kokkinn MJ, Smith BP. Intraspecific variation in odor-mediated host preference of the mosquito Culex annulirostris. J Chem Ecol. 2003;29:1889-903.

52. Standfast H, Barrow G. Studies of the epidemiology of arthropod-borne virus infections at Mitchell River Mission, Cape York Peninsula, North Queensland. Trans R Soc Trop Med Hyg. 1968;62:418-29.

53. Kilpatrick AM, Kramer LD, Campbell SR, Alleyne EO, Dobson AP, Daszak P. West Nile virus risk assessment and the bridge vector paradigm. Emerg Infect Dis. 2005;11:425.

54. Hongoh V, Berrang-Ford L, Ogden NH, Lindsay R, Scott ME, Artsob H. A review of environmental determinants and risk factors for avian-associated mosquito arboviruses in Canada. Biodiversity. 2009:10:83-91.

55. Andreadis TG. The contribution of Culex pipiens complex mosquitoes to transmission and persistence of West Nile virus in North America. J Am Mosq Cont Assoc. 2012;28:137-51.

56. Jacups SP, Carter J, Kurucz N, McDonnell J, Whelan PI. Determining meteorological drivers of salt marsh mosquito peaks in tropical northern Australia. J Vect Ecol. 2015;40:277-81.

57. Hu W, Mengersen K, Dale P, Tong S. Difference in mosquito species (Diptera: Culicidae) and the transmission of Ross River Virus between coastline and Inland Areas in Brisbane, Australia. Environ Entomol. 2010;39:88-97.

58. Stephenson EB, Peel AJ, Reid SA, Jansen CC, McCallum H. The non-human reservoirs of Ross River virus: a systematic review of the evidence. Parasit Vectors. 2018;11:188.
59. Scott TW, Amerasinghe PH, Morrison AC, Lorenz LH, Clark GG, Strickman D, et al. Longitudinal studies of Aedes aegypti (Diptera: Culicidae) in Thailand and Puerto Rico: blood feeding frequency. J Med Entomol. 2000;37:89-101.

60. Scott TW, Chow E, Strickman D, Kittayapong P, Wirtz RA, Lorenz LH, Edman JD. Blood-feeding patterns of Aedes aegypti (Diptera: Culicidae) collected in a rural Thai village. J Med Entomol. 1993;30:922-7.

61. Calvez E, Guillaumot L, Girault D, Richard V, O'Connor O, Paoaafaite T, et al. Dengue-1 virus and vector competence of Aedes aegypti (Diptera: Culicidae) populations from New Caledonia. Parasit Vectors. 2017;10:381.

62. Brady OJ, Golding N, Pigott DM, Kraemer MU, Messina JP, Reiner RC Jr, et al. Global temperature constraints on Aedes aegypti and Ae. albopictus persistence and competence for dengue virus transmission. Parasit Vectors. 2014;7:338.

63. Jansen CC, Williams CR, van den Hurk AF. The usual suspects: comparison of the relative roles of potential urban chikungunya virus vectors in Australia. PLoS One. 2015;10:e0134975.

64. González-Salazar C, Stephens CR, Sánchez-Cordero V. Predicting the potential role of non-human hosts in Zika virus maintenance. EcoHealth. 2017:14:171-7.

65. Chahad-Ehlers S, Fushita AT, Lacorte GA, de Assis PC, Del Lama SN. Effects of habitat suitability for vectors, environmental factors and host characteristics on the spatial distribution of the diversity and prevalence of haemosporidians in waterbirds from three Brazilian wetlands. Parasit Vectors. 2018:11:276.

66. Gard G, Marshall ID, Woodroof GM. Annually recurrent epidemic polyarthritis and Ross River virus activity in a coastal area of New South Wales. II. Mosquitoes, viruses and wildlife. Am J Trop Med Hyg. 1973;22:551-60.
Ready to submit your research? Choose BMC and benefit from:

- fast, convenient online submission

- thorough peer review by experienced researchers in your field

- rapid publication on acceptance

- support for research data, including large and complex data types

- gold Open Access which fosters wider collaboration and increased citations

- maximum visibility for your research: over $100 \mathrm{M}$ website views per year

At BMC, research is always in progress.

Learn more biomedcentral.com/submissions 